\title{
Clinical Study \\ Treatment of Rhinitis Sicca Anterior with Ectoine Containing Nasal Spray
}

\author{
Uwe Sonnemann, ${ }^{1}$ Olaf Scherner, ${ }^{2}$ and Nina Werkhäuser ${ }^{2}$ \\ ${ }^{1}$ Private Health Centre, Institute for ENT Elmshorn, Hermann-Ehlers-Weg 4, 25337 Elmshorn, Germany \\ ${ }^{2}$ Bitop AG, Stockumer Street 28, 58453 Witten, Germany \\ Correspondence should be addressed to Olaf Scherner; scherner@bitop.de
}

Received 28 February 2014; Accepted 17 March 2014; Published 13 April 2014

Academic Editor: Ralph Mösges

Copyright (C) 2014 Uwe Sonnemann et al. This is an open access article distributed under the Creative Commons Attribution License, which permits unrestricted use, distribution, and reproduction in any medium, provided the original work is properly cited.

\begin{abstract}
Objectives. The safety and efficacy of ectoine nasal spray and ectoine nasal spray with dexpanthenol in the treatment of rhinitis sicca were evaluated in two studies. Design and Methods. Two noninterventional observational studies were performed to evaluate the efficacy and safety of a nasal spray containing ectoine (study 1) and ectoine/dexpanthenol (study 2) over a period of two weeks including comparable numbers of patients suffering from rhinitis sicca anterior. Patients and physicians were asked to rate the efficacy in reducing symptoms and the tolerability over the treatment phase. Results. The treatment in both studies resulted in a clinical and statistical significant reduction of the main diagnosis parameters, nasal airway obstruction, and crust formation. There was also a significant reduction in the secondary diagnosis parameters in both studies. Importantly, the tolerability was very good. During the whole observational study, neither patients nor doctors stopped the medication due to unwanted effects. Conclusion. Rhinitis sicca could be successfully treated with a nasal spray containing ectoine and a nasal spray combining ectoine with dexpanthenol. The combination of both substances led to slight advantages.
\end{abstract}

\section{Introduction}

Rhinitis sicca or generally speaking dry nose is a rather frequent problem involving many people. The term "dry nose" has not yet been uniformly defined [1]. Otolaryngologists often use the terms "rhinitis sicca" or "dry rhinitis," although no clear definition exists. Many symptoms during dry nose could be encountered ranging from subjective sensation of the dry nose and itching up to mild burning, nasal obstruction, crusting associated with unpleasant smell, epistaxis, and diminished sense of smell. Rhinitis sicca anterior means a chronic inflammation in the region of the anterior part of the nose, affecting the anterior and caudal septum and/or the corresponding lateral nasal vestibule. Mechanical as well as environmental irritations lead to crust formation. In rare cases, patients suffer from a slight stench due to bacterial colonization of the crust formations. The treatment of rhinitis sicca involves mainly elimination of promoting factors, moistening, sufficient daily drinking amount, cleansing of the crusts, care of the mucosa and inhibition of possible infections, or in rare cases the elimination of overlarge endonasal space [1]. The main treatment for rhinitis sicca consists of humidification of the nose, especially the mucus, focusing in a real wash-out of possible inflammatory triggers and application of a protective layer on the mucus. The market offers a huge number of different devices involving saline, oils, moisturizers, sprays, and ointments for this purpose. Nasal irrigation and nasal saline sprays wash out inflammatory triggers directly $[2,3]$ and achieve an improvement of mucociliary clearance by improving the ciliary beat frequency $[4,5]$. Nasal ointments mostly including glycerol develop a protective moistening effect and protect the nose from water loss [6]. Low concentrated oils also have beneficial effects on nasal ciliary beat frequency [7]. The efficacy of dexpanthenol, the alcohol analog of pantothenic acid, in the treatment of rhinitis sicca is widely spread in the OTC use and has been shown clinically [8]. In addition, use of dexpanthenol has a strong tradition in the treatment of various skin diseases in which dexpanthenol is used as humidifier/ moisturizer. Also, use in wound healing has been reported [9]. Besides these different options, patients ask for alternative treatments as the current treatments often leave patients 
unsatisfied and a demand for other nonpharmacological treatment options exists.

Ectoine is an extremolyte, a compatible solute which is produced by microorganism living under extreme environmental conditions such as extreme salinity or dryness [10]. In those microorganisms, ectoine serves as natural cell protectant $[11,12]$. Different in vitro, ex vivo, and in vivo studies have shown that ectoine can be used to protect epithelial tissues and moisturize and reduce inflammations [13-15]. Ectoine acts physically via a mechanism called "preferential exclusion." In the presence of ectoine, membranes and lipids are protected indirectly: as ectoine is expelled from the surface of proteins and lipids, those are protected by a water shell, thereby increasing the fluidity of membranes and resulting in the preferential formation of the native conformation of proteins [11]. This might stabilize mucous membranes such as lining epithelia of the nose, thereby protecting those cells from invading allergens or pathogens [16]. Recent developments have demonstrated that these cell protective attributes could be transferred into medical devices including ectoine containing creams, nasal sprays, or eye drops which can be used for human use, for example, the treatment of atopic dermatitis, allergic rhinitis, and rhinosinusitis [17-20].

The use of ectoine in a saline based nasal spray could be a useful therapeutic approach for patients suffering from dry nose syndrome. Additionally a combinatory approach could be applied, for example, of ectoine and dexpanthenol. The combined effects of ectoine and/or dexpanthenol are already used in the field of dermatology and promise a useful combination effect for the treatment of rhinitis sicca. By using an ectoine and dexpanthenol nasal spray, the moisturizing and regeneration supporting effects of both compounds could assist a possible healing of ulcers and prevent nasal obstruction in addition to the reduction of primary symptoms.

\section{Materials and Methods}

The current paper describes two prospective, open-label, noninterventional trials (studies 1 and 2). Restricted inclusion of patients study based on the diagnosis of rhinitis sicca and strict adherence to the principle of nonintervention allowed data to be collected for a very unselective patient population. As study designs for both studies were very similar, data are summarized and differences are only outlined where applicable.

2.1. Medication. Patients in study 1 were treated with an ectoine containing nasal spray with $0.5 \%$ ectoine and further ingredients were sodium chloride, sodium-di-hydrogenphosphate dihydrate, di-sodium-hydrogen-phosphate, and water.

Patients in study 2 used a $0.5 \%$ ectoine nasal spray which contained $1.0 \%$ dexpanthenol, sodium chloride, sodium-dihydrogen-phosphate dihydrate, di-sodium-hydrogen-phosphate, and water.

2.2. Treatment and Study Design. Both studies were open for all patients from 18 years on, who were identified by ENT specialist with symptoms of dry nose. Following confirmation of the diagnosis of rhinitis sicca, patients were asked by the ENT specialist whether they were interested to participate in the current trials. Upon signing a patient information and consent form, patients had to attend two more site visits: V2 on day $7 \pm 2$ and $V 3$ on day $14 \pm 2$. During the entire treatment period of 2 weeks, patients were asked to use the nasal sprays at least five times daily.

2.3. Scoring of Symptoms. Clinical symptoms were assessed on a 12-point scale ranging from 0 (no symptoms) to 12 (very severe symptoms).

During the visits, the physician assessed the main symptoms of nasal obstruction and crusting of the nose as well as the following secondary symptoms: endonasal blood deposits, concomitant pharyngitis, cacosmia, rhinorrhea, exudate viscosity, and turbinate hyperplasia.

On days 3, 6, 9, and 12 after start of the study, patients were asked to document the severity of the following symptoms in a patient diary: nasal obstruction, dryness of the nose, nose bleeding, sore throat, cacosmia, and exudate from the nose. In addition, patients were asked to describe the consistency of exudate on a 12-point scale from 0 (fluid) to 12 (crusted).

\section{Scoring of Efficacy, Tolerability, and Compliance}

Both efficacy and tolerability were assessed by physicians (during V2 and V3) and by the patients (days 3, 6, 9, and 12) on a scale from 0 (very good) to 12 (none/bad).

3.1. Statistics. The statistical analysis was carried out with SPSS version 15 (study 1) or 17 (study 2), respectively. Both efficacy and safety analyses were performed on the entire study population. Descriptive statistics were used for a quantitative report of the main study population features. Continuous variables were tested for normal distribution via Kolmogorov-Smirnov test. Further analysis was carried out with the Mann-Whitney $U$ test, Wilcoxon test, or Friedman test. The level of significance was set to $P<0.05$ in all tests. Unavailable data were treated as "missing values" or substituted by the "last value carried forward" method.

\section{Results}

Both studies were conducted in accordance with the Declaration of Helsinki. All investigations were carried out with informed consent of all participants.

Study 1 was a noninterventional trial taking place from April to July 2008; study 2 took place from March to April 2009. Both studies were carried out at a German ear nose throat (ENT) practice. Distribution and demographics of patients are shown in Figures 1 and 2.

\subsection{Development of Symptoms}

4.1.1. Nasal Obstruction. In both studies, the investigators assessment revealed that the symptom nasal obstruction decreased significantly from V1 to V2 as well as further to V3. 


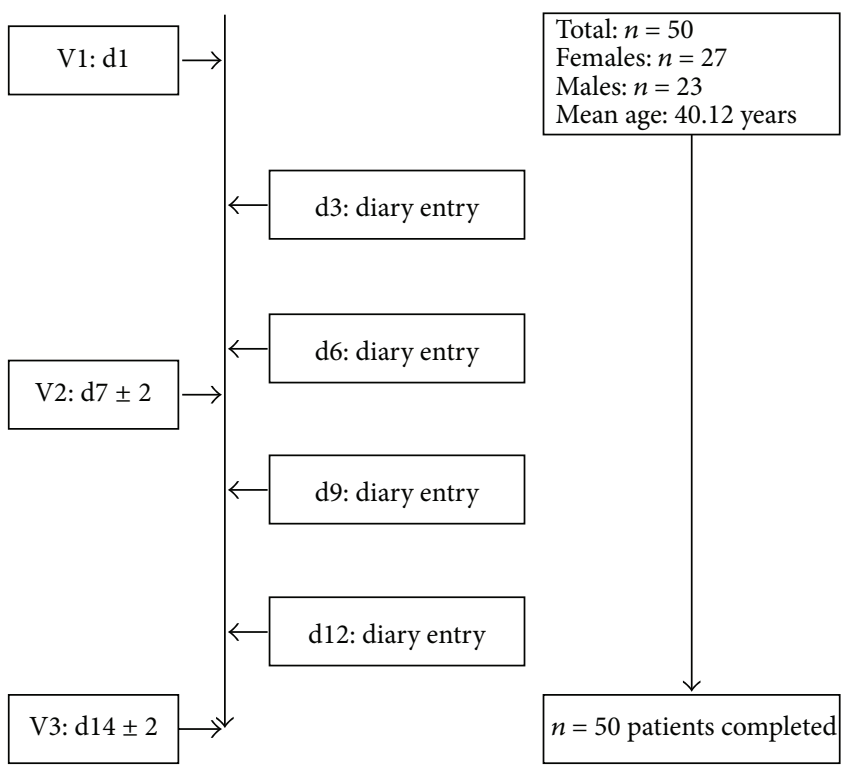

FIgure 1: Patient flow and characteristics of demographic data in study 1 .

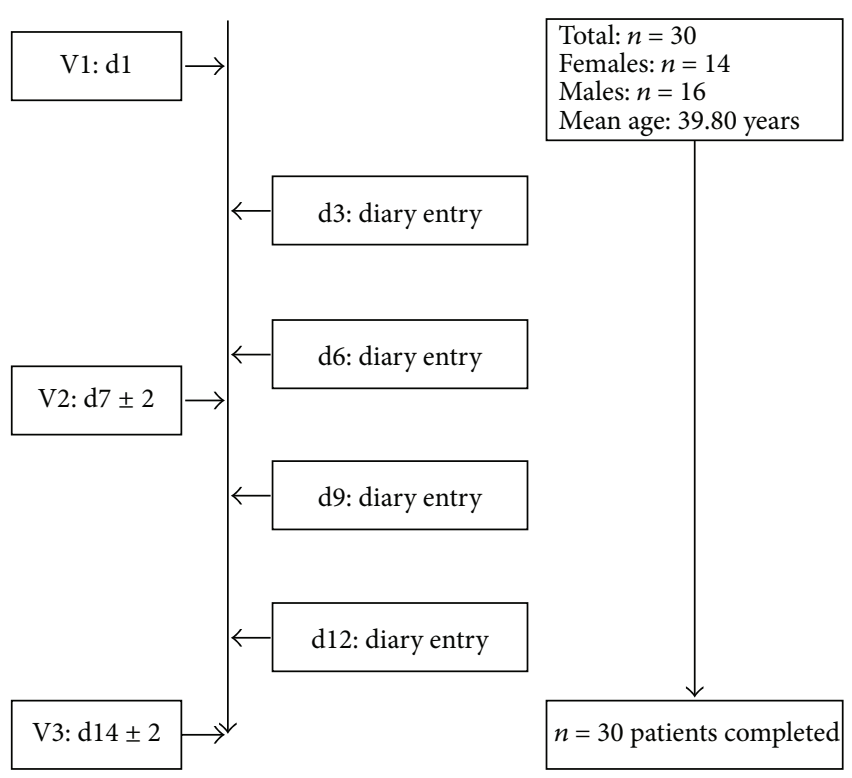

FIGURE 2: Patient flow and characteristics of demographic data in study 2.

In study 1 , symptom scores decreased from baseline values $4.60 \pm 2.23$ at $\mathrm{V} 1$ to $2.74 \pm 1.95$ at $\mathrm{V} 2$ and then to $1.54 \pm 1.52$ at V3. Values in study 2 decreased comparably from $5.43 \pm 1.46$ at V1 to $2.23 \pm 2.05$ at V2 and further to $1.73 \pm 1.89$ at V3 (Figures 3 and 4 ).

Decreases of the symptom nasal obstruction were similar and in accordance with the patients' assessments. Values are listed in Table 1.

4.1.2. Crust Formation/Nasal Dryness. The symptom nasal crust formation decreased significantly from V1 to V2 and

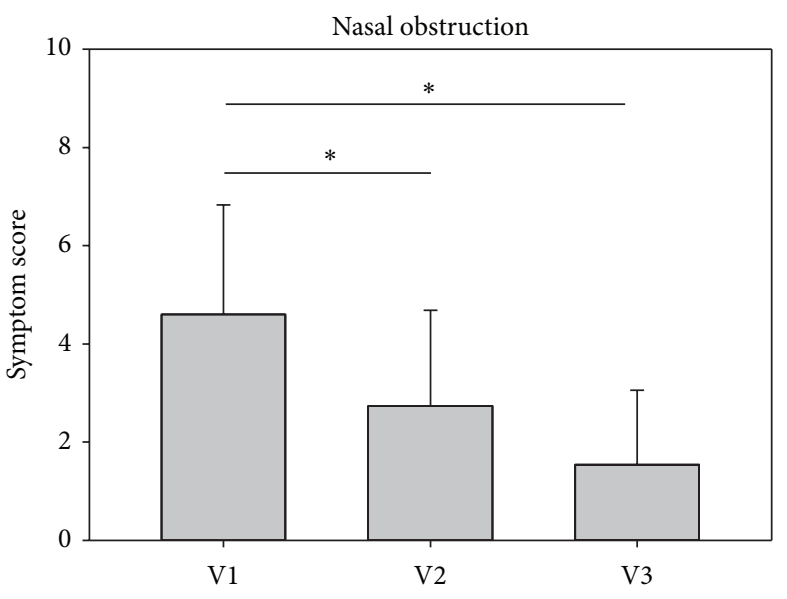

FIGURE 3: Development of nasal obstruction from V1 to V3 assessed by the investigator (study 1 ). The asterisks mark a statistical significance; the whiskers mark the standard deviation.

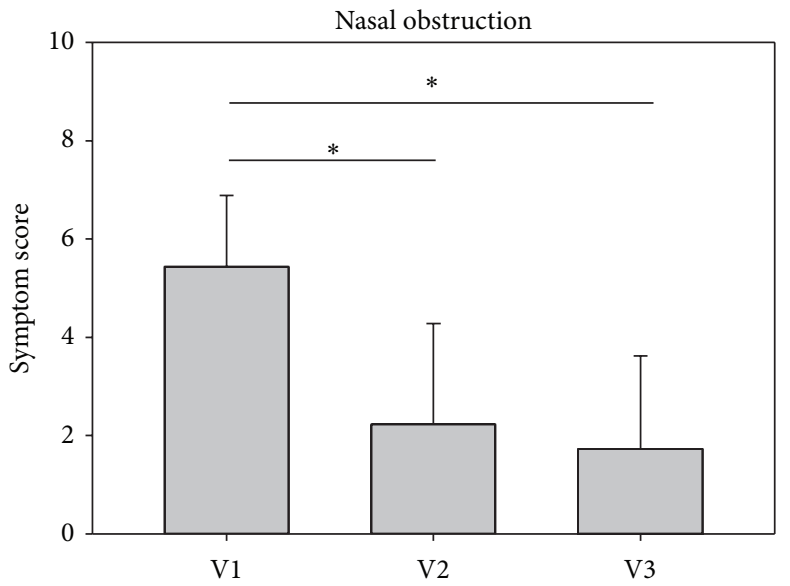

Figure 4: Development of nasal obstruction from V1 to V3 assessed by the investigator (study 2). The asterisks mark a statistical significance; the whiskers mark the standard deviation.

further to V3 in both studies in the investigators assessment. Values in study 1 decreased from baseline values of $6.20 \pm 1.99$ to $2.16 \pm 2.26$ at $\mathrm{V} 2$ and further to $1.52 \pm 1.85$ at $\mathrm{V} 3$. Values in study 2 decreased comparably from baseline values of $6.43 \pm$ 2.08 to $2.40 \pm 1.81$ at V2 and to $1.30 \pm 1.24$ at V3. Results are depicted in Figures 5 and 6.

Patients evaluated the decrease of the symptom dry nose in a similar way to the physician's assessments as listed in Table 2. The symptom nasal dryness decreased significantly from day 3 to day 12 in both studies.

4.1.3. Secondary Symptom Scores. In addition to the symptoms nasal obstruction and crust formation/nasal dryness, further symptoms were assessed by both investigators and patients. As depicted in Figures 7 and 8, there was a similarity between the results of both studies in the investigators assessment. The symptoms blood deposits, pharyngitis, turbinate hyperplasia, and exudate viscosity improved significantly 


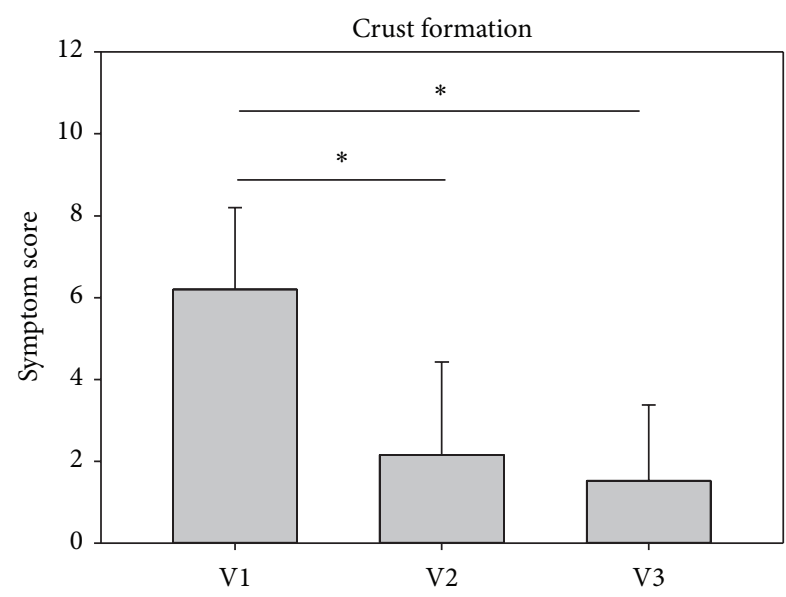

FIgURE 5: Development of crust formation from visit 1 (V1) to visit 3 (V3) in study $1 .{ }^{*} P<0.001$. The asterisks mark a statistical significance; the whiskers mark the standard deviation.

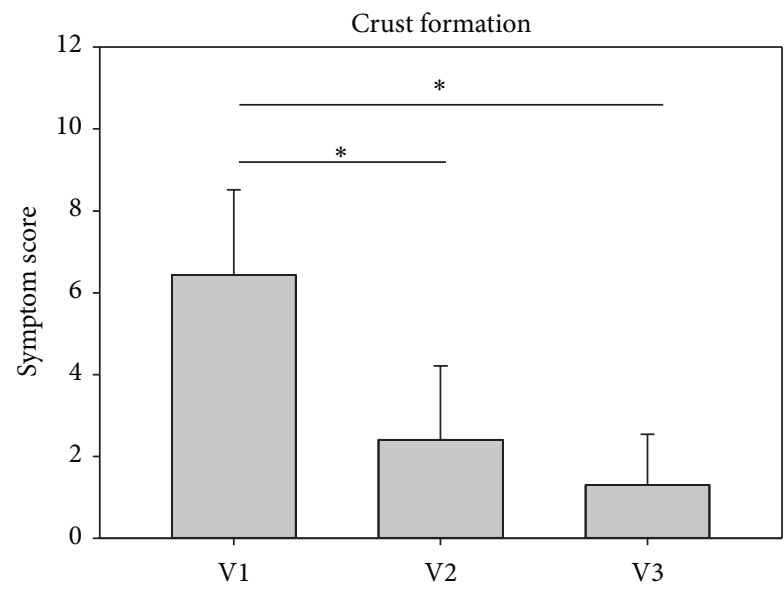

FIGURE 6: Development of crust formation from visit 1 (V1) to visit 3 (V3) in study $2 .{ }^{*} P<0.001$.

from baseline values at V1 to the final visit V3. The symptom rhinorrhea only improved significantly in study 2, whereas decreases in this symptom were nonsignificant in study 1 . As only very few patients complained about the symptom cacosmia ( $n=2$ in study 1 and $n=5$ in study 2 ), decreases in this symptom were negligible.

Patients' scores of secondary symptom evaluation are listed in Tables 3 and 4. In study 1, the symptom rhinorrhea improved significantly from $\mathrm{d} 3$ to $\mathrm{d} 12$. In study 2 , nose bleeding, rhinorrhea, cacosmia, and exudate viscosity improved significantly over this time frame.

\section{Efficacy, Tolerability, and Compliance}

The physician judged both efficacy and tolerability of treatment after 7 days (V2) and after 14 days (V3). As shown in Figures 9 and 10, ectoine nasal spray treatment was considered to be both efficient and well tolerable. Mean values for efficacy at V3 were $3.5 \pm 2.06$ (study 1) and $1.83 \pm 1.39$ (study 2) meaning good to very good efficacy. Mean values for tolerability were $2.08 \pm 1.21$ (study 1 ) and $0.57 \pm 0.97$ (study 2 ), which also means good to very good tolerability.

Patients' assessments of tolerability and efficacy of treatment are depicted in Figures 11 and 12. Mean efficacy values were $3.12 \pm 3.08$ at day 12 of treatment in study 1 and $2.43 \pm 2.24$ in study 2 corresponding to good efficacy. Tolerability was judged as very good in both studies with mean values on day 12 of $1.40 \pm 1.80$ in study 1 and $1.17 \pm 1.21$ in study 2 .

5.1. Adverse Events (AEs). In study 1, no AE occurred. In study 2, $1 \mathrm{AE}$ occurred (acute rhinitis). The correlation with the treatment was judged as unlikely by the investigator. No SAE occurred in either of the two studies.

\section{Conclusions}

The aim of these observational studies was to gain insight into the tolerability and the extent to which the treatments influenced the severity of the patients' symptoms. An ectoine nasal spray (study 1) or an ectoine and dexpanthenol nasal spray (study 2) was tested in patients with rhinitis sicca under practical conditions. A total of 80 patients (50 patients in study 1,30 patients in study 2) with a wide variety of disease severities participated in this postmarketing surveillance study. However, the potential flaw of these studies is their noncontrolled character, the missing randomization, or placebo control. Therefore the evidence grade of the results needs to be reduced at least to IIb.

Both nasal spray formulations showed a good tolerability and safety in the studies. No drop-out was recorded. The studies showed a significant decrease of the main symptoms nasal obstruction and crust formation from V1 to V2 as well as further to V3. The decrease of nasal obstructions assessed by the physicians was confirmed by patients in both studies, with a stronger decrease of symptoms assessed by the physicians. This is likely to be due to the timing of the patient's diary, as this was started at day three of treatment, when the first positive effect of the respective treatments had occurred already.

Apart from main symptoms, the secondary symptom scores also decreased similarly in both studies. In the investigators assessment, the symptoms blood deposits, pharyngitis, turbinate hyperplasia, and exudate viscosity improved significantly from starting values at V1 to the final visit V3. Differences in symptom reduction between both studies occurred only with respect to rhinorrhea. Treatment with the nasal spray with ectoine only did not lead to a significant improvement of rhinorrhea, whereas the improvement in with the ectoine nasal spray alone was not statistically significant. The degree of symptom reduction in the main parameter nasal obstruction seemed to be reduced more efficiently in the study with the combined nasal spray, as the score started with a higher value and dropped faster and to a higher degree as in the study with the ectoine nasal spray. In the patient assessment of study 2 symptom improvement was significant for nose bleeding, exudate viscosity, rhinorrhea, and cacosmia, whereas the patient assessment in study 1 showed only a significant reduction of the symptoms in nose 
TABLE 1: Development of nasal obstruction assessed by patients on days 3, 6, 9, and 12 following treatment with ectoine nasal spray.

\begin{tabular}{cccccc}
\hline & $\mathrm{d} 3$ & $\mathrm{~d} 6$ & $\mathrm{~d} 9$ & $\mathrm{~d} 12$ & \\
\hline Study 1 & $2.74 \pm 2.31$ & $2.52 \pm 2.18$ & $2.10 \pm 2.00$ & $1.64 \pm 1.68$ & $P(\mathrm{~d} 3$ versus d12) \\
Study 2 & $3.67 \pm 2.28$ & $2.80 \pm 1.99$ & $2.33 \pm 1.65$ & $1.87 \pm 1.33$ & $<0.001$ \\
\hline
\end{tabular}

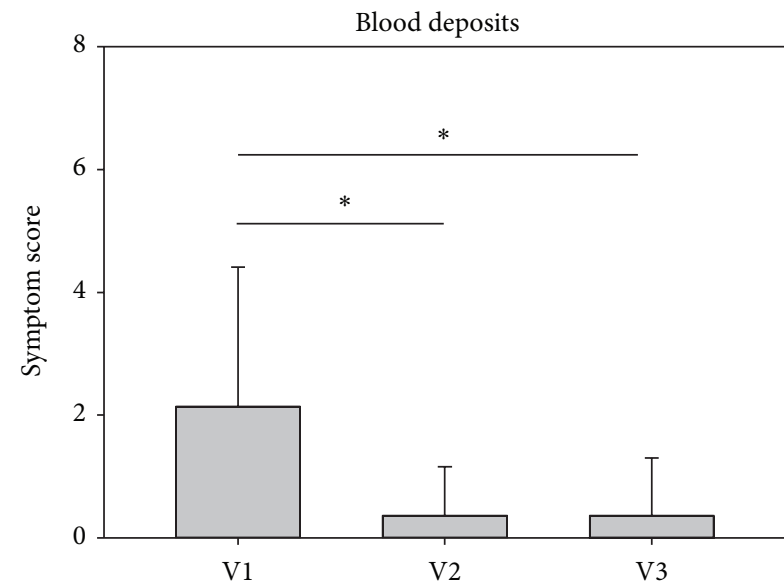

(a)

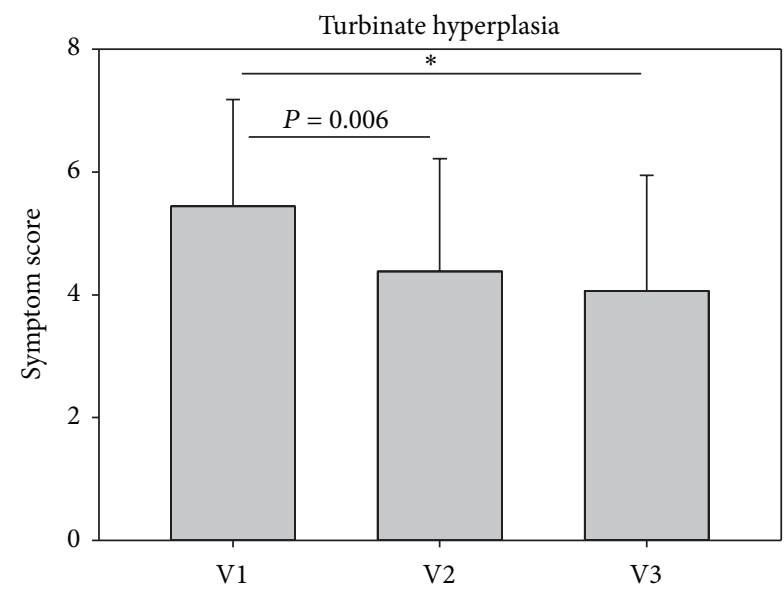

(c)

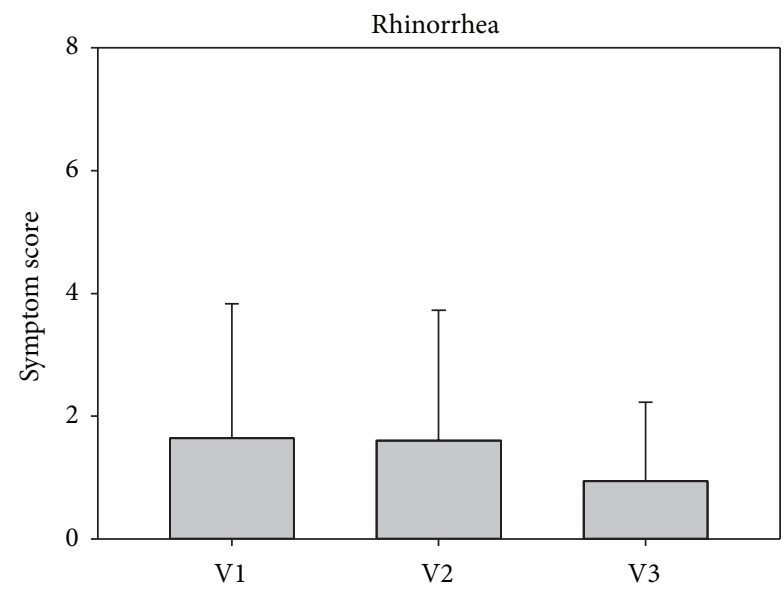

(e)

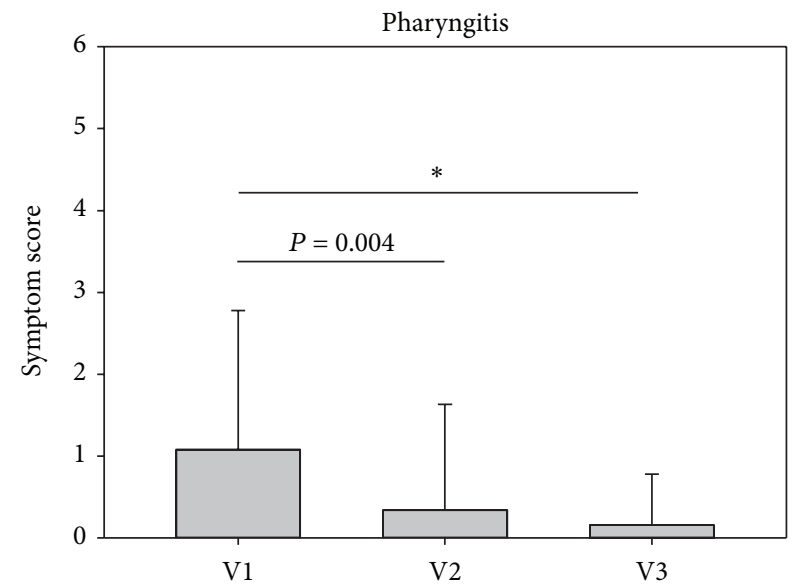

(b)

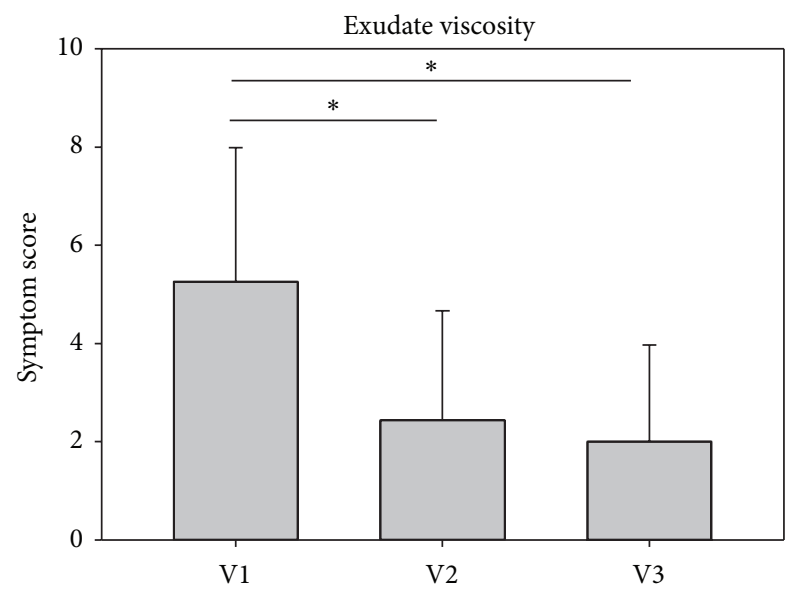

(d)

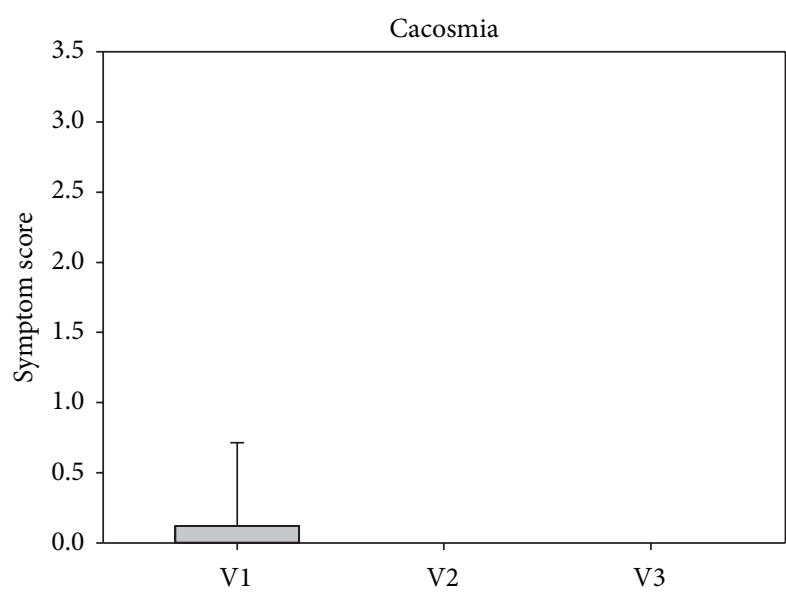

(f)

Figure 7: Development of secondary symptoms (ENT evaluation) during study $1 .{ }^{*} P<0.001$. The asterisks mark a statistical significance; the whiskers mark the standard deviation. 
TABLE 2: Development of nasal dryness assessed by patients on days 3, 6, 9, and 12 following treatment with ectoine nasal spray.

\begin{tabular}{lccccc}
\hline & $\mathrm{d} 3$ & $\mathrm{~d} 6$ & $\mathrm{~d} 9$ & $\mathrm{~d} 12$ & \\
\hline Study 1 & $4.64 \pm 2.40$ & $3.76 \pm 2.53$ & $2.90 \pm 2.48$ & $2.42 \pm 2.37$ & $P(\mathrm{~d} 3$ versus d12) \\
Study 2 & $4.43 \pm 2.49$ & $3.30 \pm 2.12$ & $2.33 \pm 1.97$ & $1.83 \pm 1.49$ & $<0.001$ \\
\hline
\end{tabular}

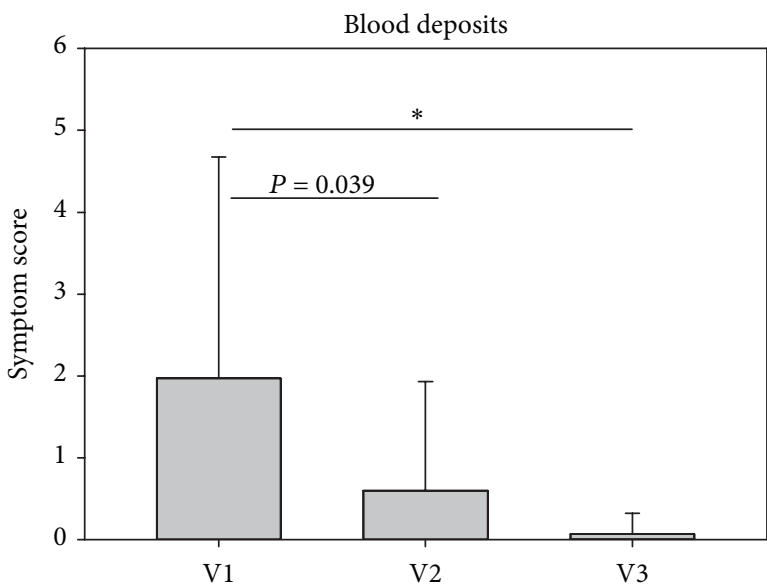

(a)

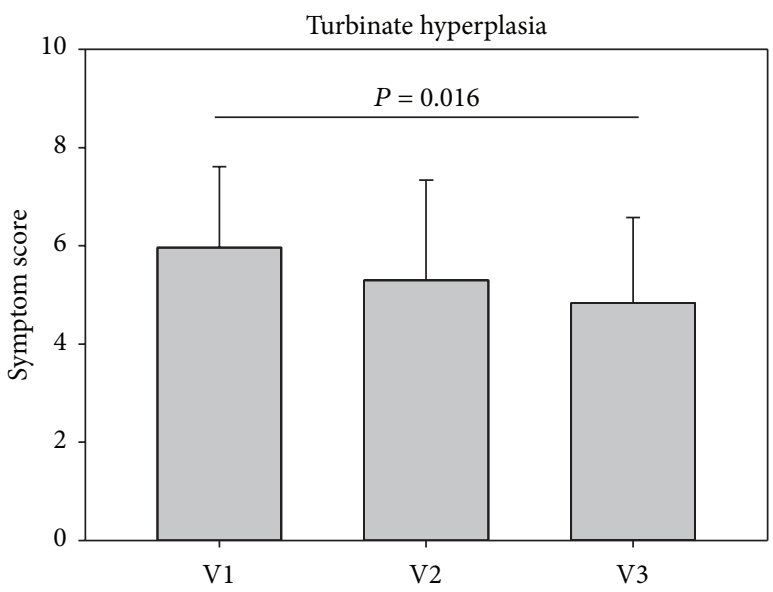

(c)

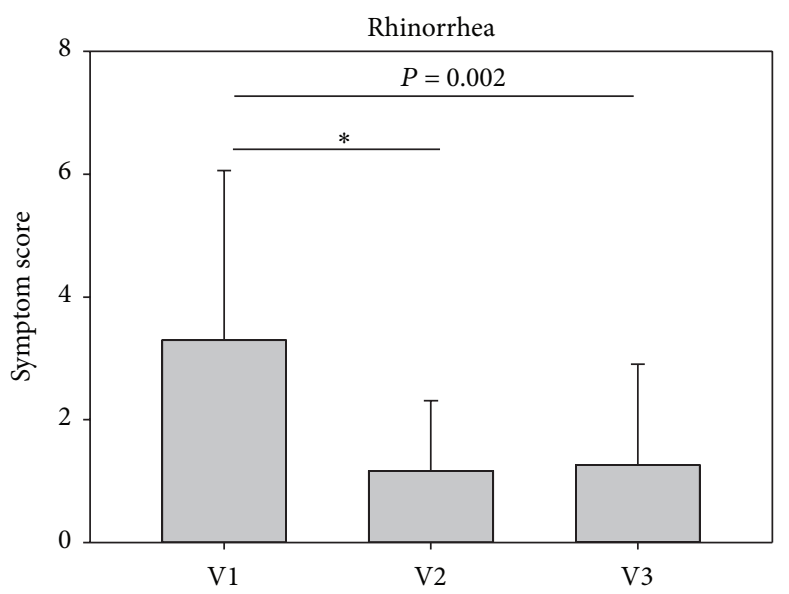

(e)

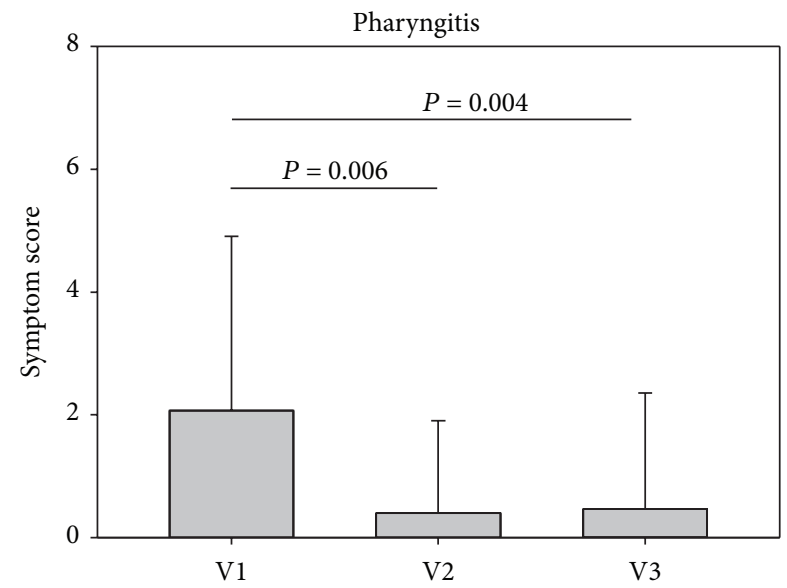

(b)

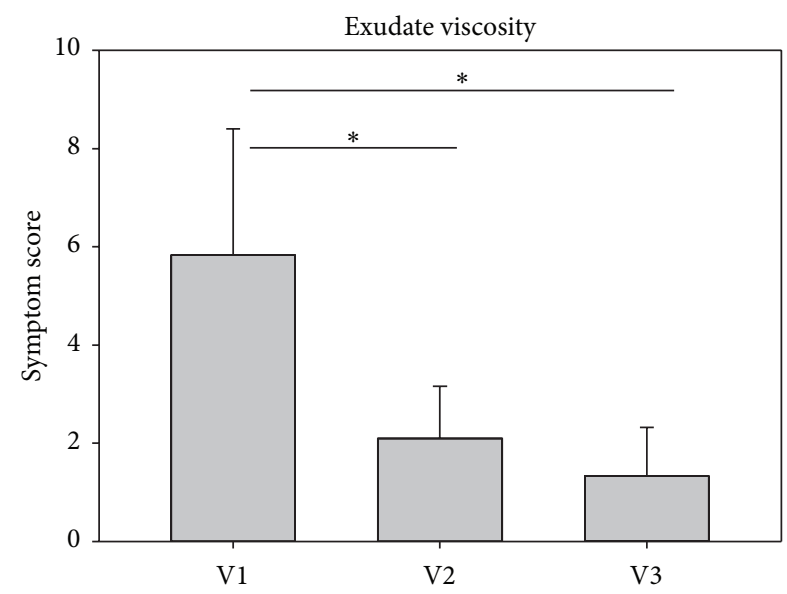

(d)

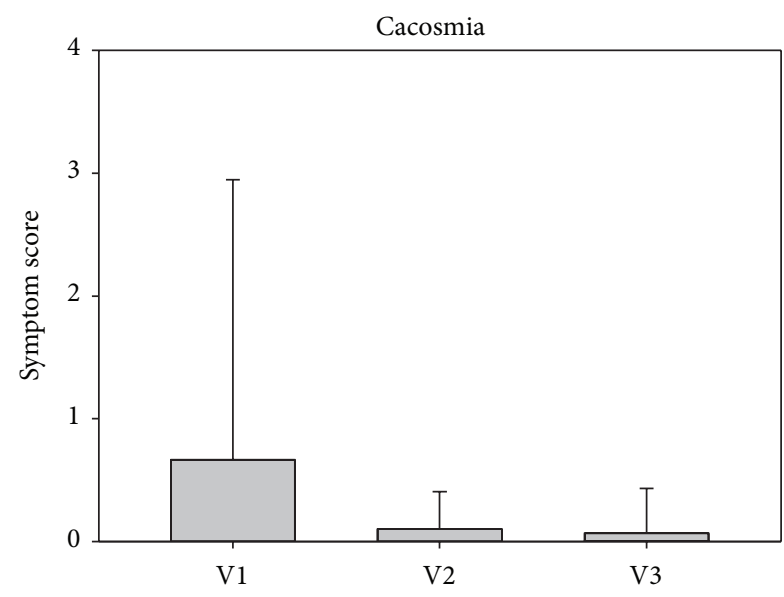

(f)

FIgURE 8: Development of secondary symptoms during study $2 .{ }^{*} \mathrm{P}<0.001$. 
TABle 3: Patients' assessments of secondary symptom scores at days 3, 6, 9, and 12 following treatment start of study 1.

\begin{tabular}{lccccc}
\hline Symptoms & $\mathrm{d} 3$ & $\mathrm{~d} 6$ & $\mathrm{~d} 9$ & $\mathrm{~d} 12$ & $P$ value (d3 versus d12) \\
\hline Nose bleeding & $0.36 \pm 0.85$ & $0.46 \pm 1.07$ & $0.36 \pm 0.85$ & $0.30 \pm 0.74$ & 0.787 \\
Pharyngitis & $0.64 \pm 1.77$ & $0.62 \pm 1.74$ & $0.46 \pm 1.20$ & $0.42 \pm 1.13$ & 0.754 \\
Exudate viscosity & $3.36 \pm 3.50$ & $2.90 \pm 3.03$ & $2.38 \pm 2.86$ & $2.40 \pm 2.93$ & 0.108 \\
Rhinorrhea & $2.44 \pm 2.16$ & $2.10 \pm 2.14$ & $1.74 \pm 1.88$ & $1.42 \pm 1.54$ & 0.021 \\
Cacosmia & $0.60 \pm 1.53$ & $0.48 \pm 1.31$ & $0.42 \pm 1.57$ & $0.26 \pm 0.69$ & 0.388 \\
\hline
\end{tabular}

TABle 4: Patients' assessments of secondary symptom scores at days 3, 6, 9, and 12 following treatment start of study 2.

\begin{tabular}{lccccc}
\hline Symptoms & $\mathrm{d} 3$ & $\mathrm{~d} 6$ & $\mathrm{~d} 9$ & $\mathrm{~d} 12$ & $P$ value $(\mathrm{d} 3$ versus d12) \\
\hline Nose bleeding & $0.70 \pm 1.60$ & $0.73 \pm 1.72$ & $0.50 \pm 1.01$ & $0.17 \pm 0.59$ & 0.0019 \\
Pharyngitis & $1.07 \pm 2.26$ & $0.67 \pm 1.63$ & $0.57 \pm 1.19$ & $0.60 \pm 1.00$ & 0.719 \\
Exudate viscosity & $2.67 \pm 2.38$ & $2.50 \pm 2.64$ & $2.10 \pm 2.23$ & $1.67 \pm 2.19$ & 0.027 \\
Rhinorrhea & $2.57 \pm 1.99$ & $2.00 \pm 1.72$ & $1.90 \pm 1.83$ & $1.57 \pm 1.45$ & 0.025 \\
Cacosmia & $0.90 \pm 2.26$ & $0.70 \pm 1.82$ & $0.33 \pm 0.99$ & $0.30 \pm 0.99$ & 0.005 \\
\hline
\end{tabular}

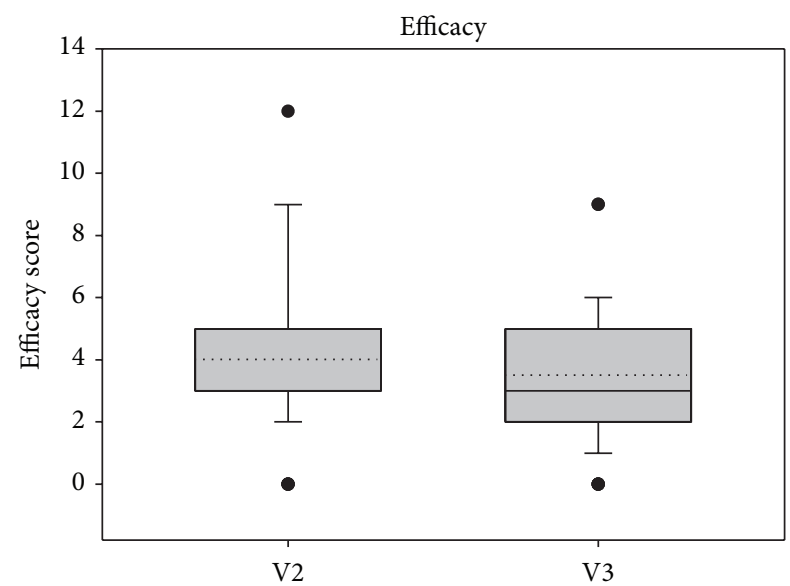

(a)

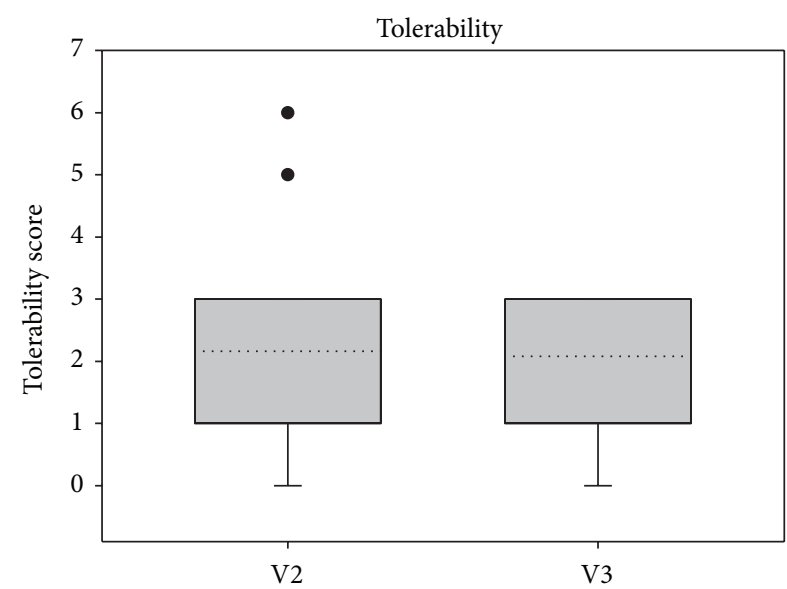

(b)

FIGURE 9: Judgment of efficacy and tolerability according to the physician's assessment in study 1.

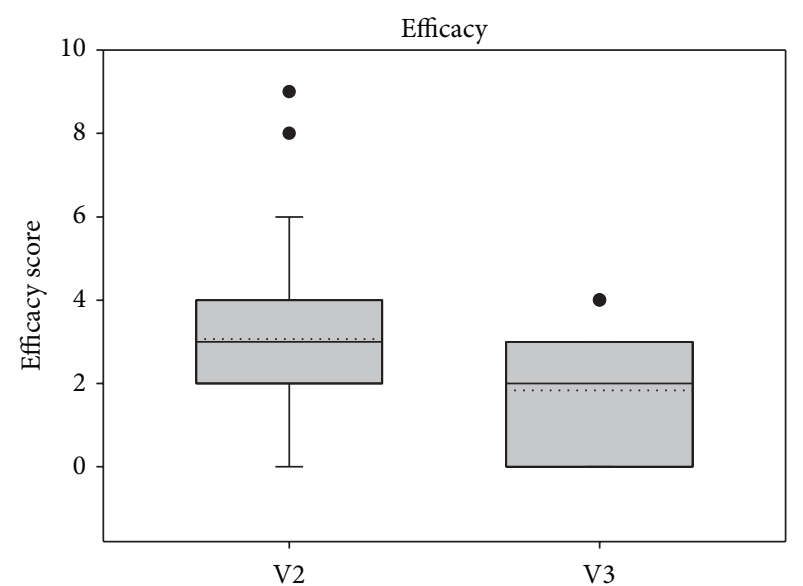

(a)

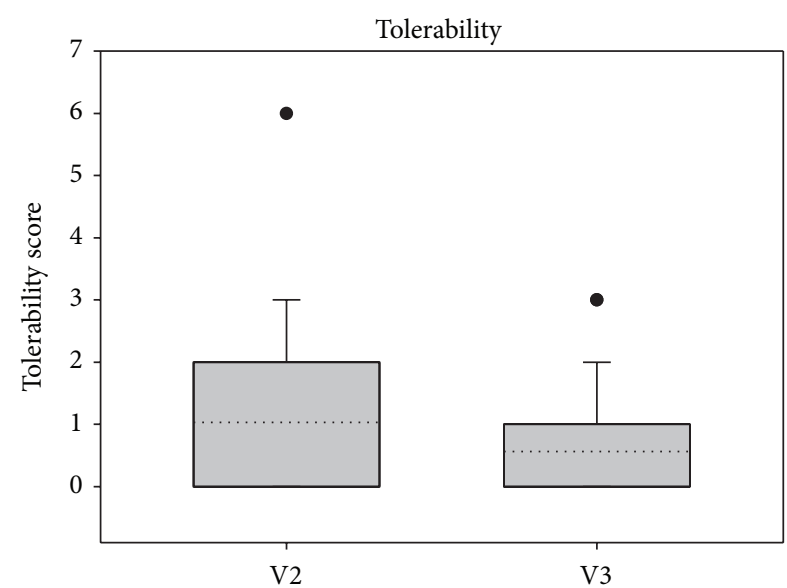

(b)

Figure 10: Judgment of efficacy and tolerability according to the physician's assessment in study 2. 


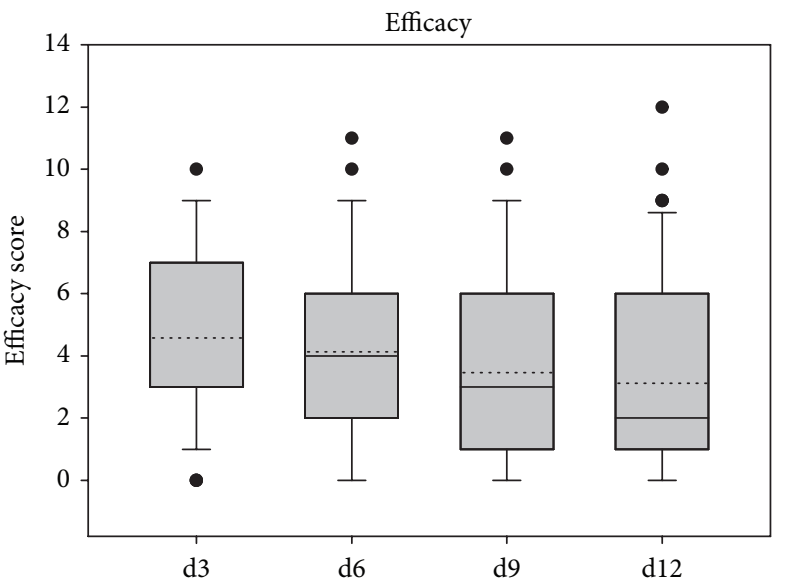

(a)

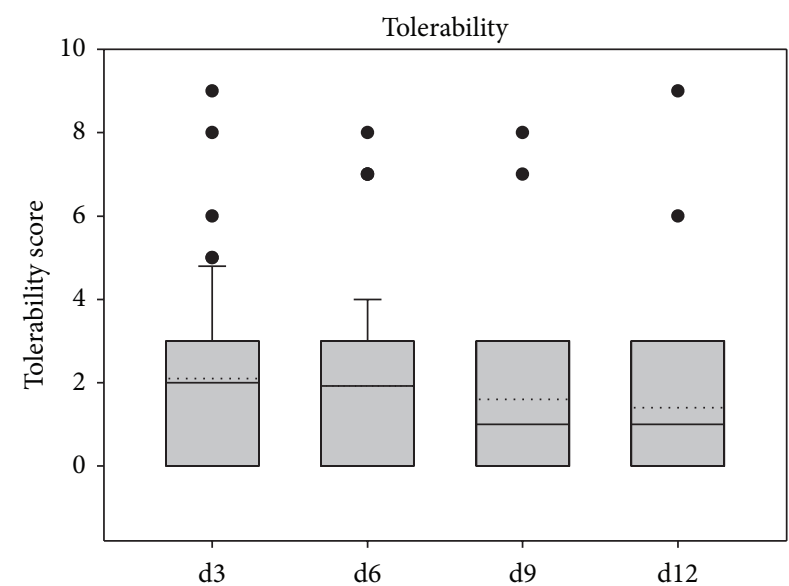

(b)

FIGURE 11: Judgment of efficacy and tolerability according to the patients' assessment in study 1.

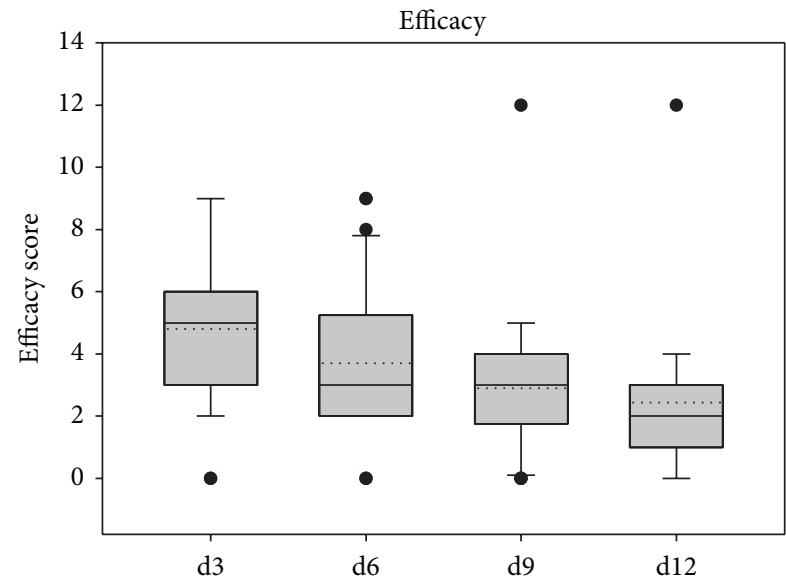

(a)

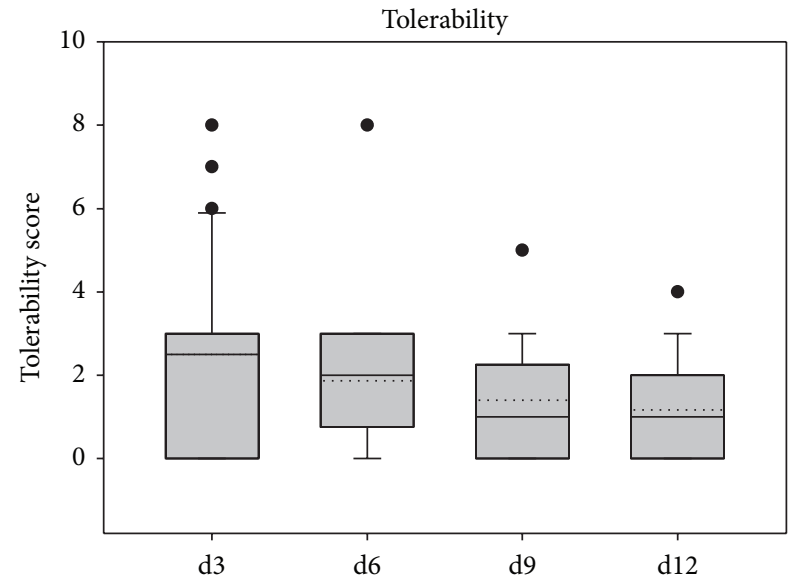

(b)

FIGURE 12: Judgment of efficacy and tolerability according to the patients' assessment in study 2.

bleeding. It can be mentioned that only a few patients in both studies suffered from cacosmia and the decreases in these symptoms were negligible for both of them.

As a summary, the ectoine nasal spray achieved in study 1 treatment success similar to that of the combination of ectoine and dexpanthenol in study 2 with respect to the main symptom scores of both studies, crust formation and nasal obstruction. Differences in treatment effect between both nasal sprays and studies were observable in the secondary parameters, both in physicians and in patients assessment, tending towards an additional effect if ectoine and dexpanthenol are combined in one product compared to ectoine alone. Both natural nonpharmacological nasal sprays showed efficacy in treatment of rhinitis sicca, which is comparable to the reported outcome for other products [21]. Data from preclinical studies also support the combination of ectoine and dexpanthenol (data not shown).

The mode of action and subsequent effect in treatment of rhinitis sicca of dexpanthenol is understood from the literature [22]. The treatment effects of the ectoine nasal spray can be attributed to its physical action. By increasing the fluidity of the nasal epithelia, the barrier function of this membrane is increased, therefore inhibiting the potential loss of water. Experiments with ectoine on biological and artificial membranes support this thesis further, including the reduction of mechanical stress induced membrane damage [15-17]. The additional hydrating effect of ectoine is well described in the literature $[15,23,24]$ as well as the capacity of reduction of inflammation in skin and respiratory epithelium $[14,17,18,25]$.

Taken together, rhinitis sicca anterior or dry nose could be successfully treated with an ectoine containing nasal spray. Therefore an interesting option of a new and safe nonpharmacological treatment of rhinitis sicca will be available in the future. The addition of the well-known and accepted dexpanthenol did not enhance the treatment regarding the major symptoms scores. The decrease of symptom over the 14-day treatment period was more pronounced for the 
combination of ectoine and dexpanthenol, but this difference was not significant. Slightly better improvement in different secondary symptoms revealed synergistic characteristics of the two substances in combination when compared to the ectoine nasal spray alone. However, these findings came from two independent noncontrolled trials. Therefore additional controlled trials are suggested to further prove the efficacy of ectoine nasal spray with or without dexpanthenol.

\section{Disclosure}

Dr. O. Scherner and Nina Werkhäuser are employees of Bitop AG, a company where medical devices, including the ectoine nasal spray, were developed and registered. Bitop AG sponsored the trials discussed in this paper. Dr. Uwe Sonnemann received sponsorship by Bitop AG to conduct the studies.

\section{Conflict of Interests}

The authors declare that there is no conflict of interests regarding the publication of this paper.

\section{Acknowledgment}

The authors thank Dr. T. Kottmann for statistical analysis of data.

\section{References}

[1] T. Hildenbrand, R. K. Weber, and D. Brehmer, "Rhinitis sicca, dry nose and atrophic rhinitis: a review of the literature," European Archives of Oto-Rhino-Laryngology, vol. 268, no. 1, pp. $17-26,2011$.

[2] C. L. Brown and S. M. Graham, "Nasal irrigations: good or bad?" Current Opinion in Otolaryngology \& Head and Neck Surgery, vol. 12, no. 1, pp. 9-13, 2004.

[3] O. Michel, "Nasenspülung bei rhinosinusitis," Laryngo-RhinoOtologie, vol. 85, no. 6, pp. 448-458, 2006.

[4] W. M. Boek, N. Keleş, K. Graamans, and E. H. Huizing, "Physiologic and hypertonic saline solutions impair ciliary activity in vitro," Laryngoscope, vol. 109, no. 3, pp. 396-399, 1999.

[5] A. R. Talbot, T. M. Herr, and D. S. Parsons, "Mucociliary clearance and buffered hypertonic saline solution," Laryngoscope, vol. 107 , no. 4, pp. 500-503, 1997.

[6] M. Miwa, N. Nakajima, M. Matsunaga, and K. Watanabe, "Measurement of water loss in human nasal mucosa," American Journal of Rhinology, vol. 20, no. 5, pp. 453-455, 2006.

[7] A. Neher, M. Gstöttner, M. Thaurer, P. Augustijns, M. Reinelt, and W. Schobersberger, "Influence of essential and fatty oils on ciliary beat frequency of human nasal epithelial cells," American Journal of Rhinology, vol. 22, no. 2, pp. 130-134, 2008.

[8] W. Kehrl and U. Sonnemann, "Dexpanthenol-nasenspray als wirksames therapieprinzip zur behandlung der rhinitis sicca anterior," Laryngo-Rhino-Otologie, vol. 77, no. 9, pp. 506-512, 1998.

[9] M. Dohil, "Natural ingredients in atopic dermatitis and other inflammatory skin disease," Journal of Drugs in Dermatology, vol. 12, supplement 9, pp. S128-S132, 2011.
[10] E. A. Galinski and A. Oren, "Isolation and structure determination of a novel compatible solute from the moderately halophilic purple sulfur bacterium Ectothiorhodospira marismortui," European Journal of Biochemistry, vol. 198, no. 3, pp. 593-598, 1991.

[11] T. Arakawa and S. N. Timasheff, "The stabilization of proteins by osmolytes," Biophysical Journal, vol. 47, no. 3, pp. 411-414, 1985.

[12] J. Smiatek, R. K. Harishchandra, O. Rubner, H.-J. Galla, and A. Heuer, "Properties of compatible solutes in aqueous solution," Biophysical Chemistry, vol. 160, no. 1, pp. 62-68, 2012.

[13] J. Buenger and H. Driller, "Ectoin: an effective natural substance to prevent UVA-induced premature photoaging," Skin Pharmacology and Physiology, vol. 17, no. 5, pp. 232-237, 2004.

[14] U. Sydlik, I. Gallitz, C. Albrecht, J. Abel, J. Krutmann, and K. Unfried, "The compatible solute ectoine protects against nanoparticle-induced neutrophilic lung inflammation," American Journal of Respiratory and Critical Care Medicine, vol. 180, no. 1, pp. 29-35, 2009.

[15] R. Graf, S. Anzali, J. Buenger, F. Pfluecker, and H. Driller, "The multifunctional role of ectoine as a natural cell protectant," Clinics in Dermatology, vol. 26, no. 4, pp. 326-333, 2008.

[16] K. Unfried, U. Sydlik, H. Peuschel, C. Albrecht, A. Bilstein, and J. Krutmann, "The compatible solute ectoine prevents neutrophilic lung inflammation induced by environmental model nanoparticles in vivo," Toxicology Letters, vol. 196, p. S67, 2010.

[17] A. Marini, K. Reinelt, J. Krutmann, and A. Bilstein, "Ectoinecontaining cream in the treatment of mild to moderate atopic dermatitis: a randomised, comparator-controlled, intra-individual double-blind, multi-center trial," Skin Pharmacology and Physiology, vol. 27, pp. 57-65, 2014.

[18] A. Eichel, J. Wittig, K. Sha-Hosseini, and R. Mösges, "A prospective, controlledstudy of SNS01 (ectoine nasal spray) compared to BNO-101 (phytotherapeutic dragées) in patients with acute rhinosinusitis," Current Medical Research and Opinion, vol. 29, no. 7, pp. 739-746, 2013.

[19] M. Böhm, A. Michels, and R. Mösges, "Pharmaotherapie: therapeutischer stand der allergischen rhinits," Forum HNO, vol. 14, pp. 156-161, 2012.

[20] A. Salapatek, M. Bates, A. Bilstein, and D. Patel, "Ectoin, a novel, non-drug, extremophile-based device, relieves allergic rhinoconjunctivitis symptoms in patients in an environmental exposure chamber model," The Journal of Allergy and Clinical Immunology, vol. 127, supplement 2, p. 202, 2011.

[21] C. Hahn, M. Böhm, S. Allekotte, and R. Mösges, “Tolerability and effects on quality of life of liposomal nasal spray treatment compared to nasal ointment containing dexpanthenol or isotonic $\mathrm{NaCl}$ spray in patients with rhinitis sicca," European Archives of Oto-Rhino-Laryngology, vol. 270, no. 9, pp. 24652472, 2013.

[22] W. Kehrl and U. Sonnemann, "Dexpanthenol nasal spray as an effective therapeutic principle for treatment of rhinitis sicca anteriory," Laryngo-Rhino-Otologie, vol. 77, no. 9, pp. 506-512, 1998.

[23] J. Bünger, J. Degwert, and H. Driller, "The protective function of compatible solute ectoin on the skin cells and its biomolecules with respect to UV-ratiation, immunosupression and membrane damage," IFSCC Magazine, vol. 4, no. 2, pp. 1-6, 2001.

[24] U. Heinrich, B. Garbe, and H. Tronnier, "In vivo assessment of ectoin: a randomized, vehicle-controlled clinical trial," Skin Pharmacology and Physiology, vol. 20, no. 4, pp. 211-218, 2007.

[25] H. Peuschel, U. Sydlik, S. Grether-Beck et al., "Carbon nanoparticles induce ceramide- and lipid raft-dependent signalling 
in lung epithelial cells: a target for a preventive strategy against environmentally-induced lung inflammation," Particle and Fibre Toxicology, vol. 9, article 48, 2012. 


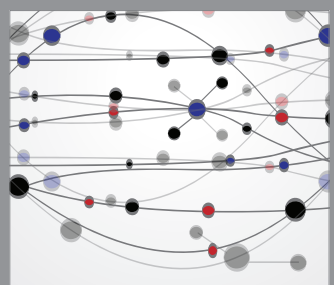

The Scientific World Journal
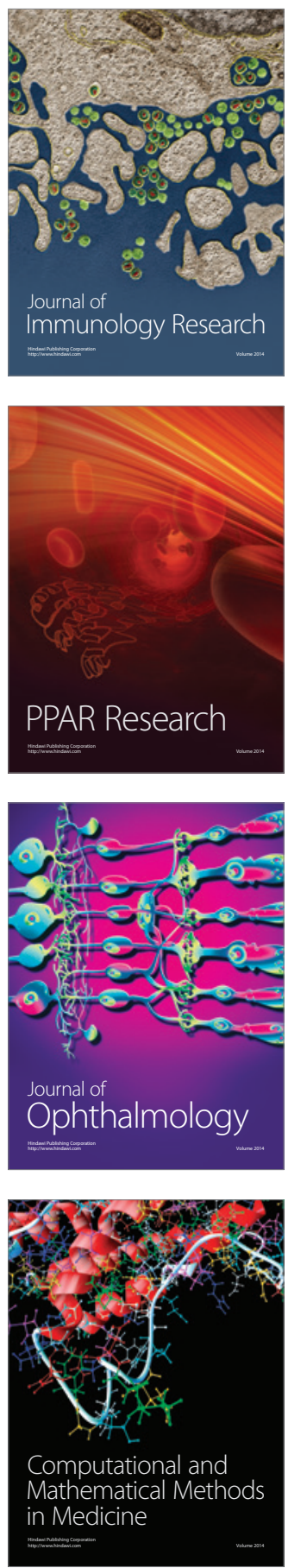

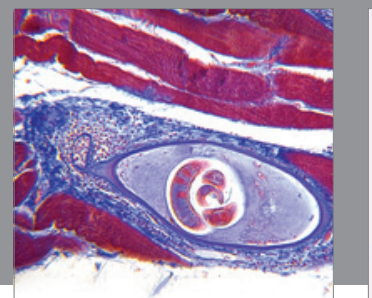

Gastroenterology

Research and Practice
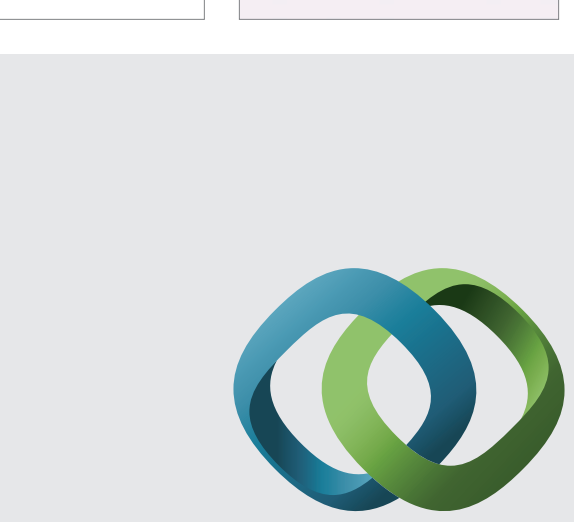

\section{Hindawi}

Submit your manuscripts at

http://www.hindawi.com
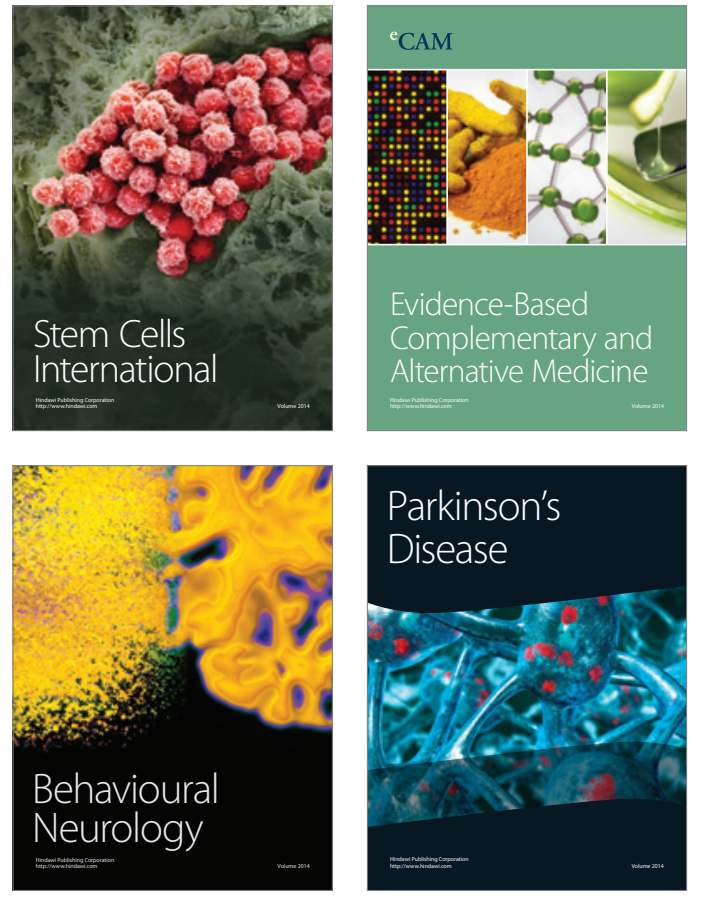
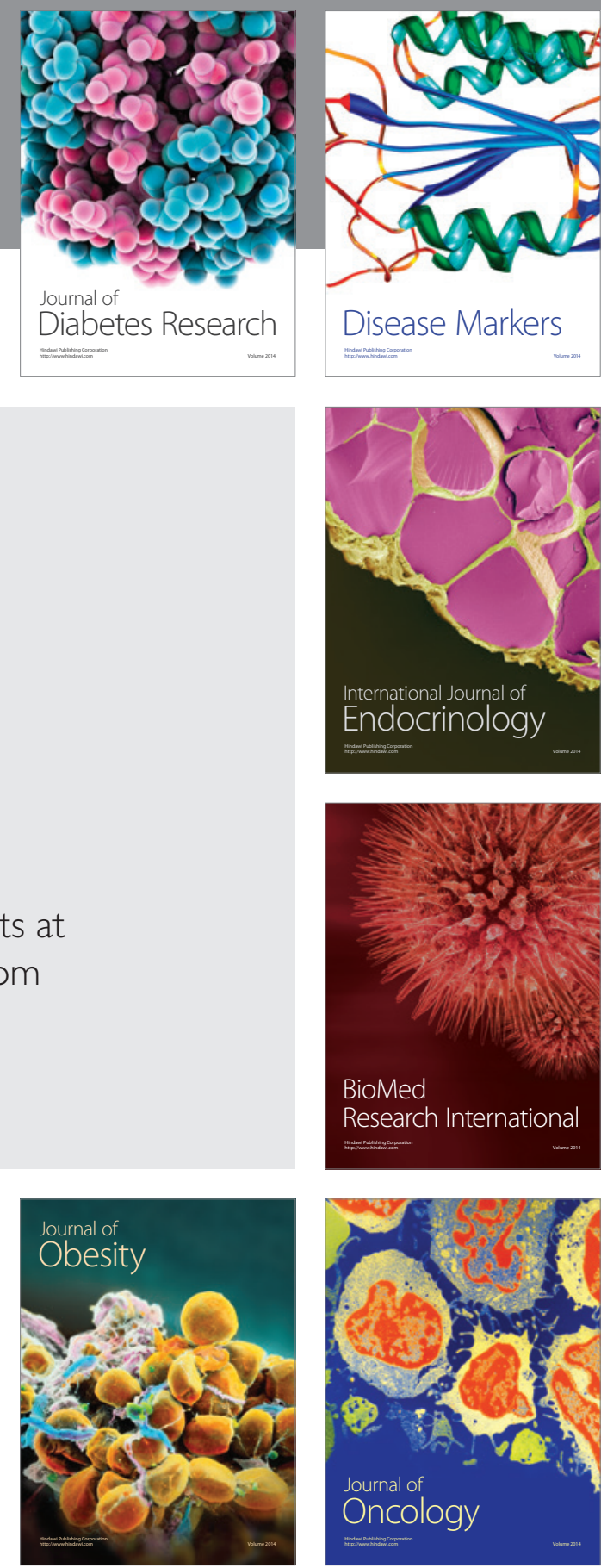

Disease Markers
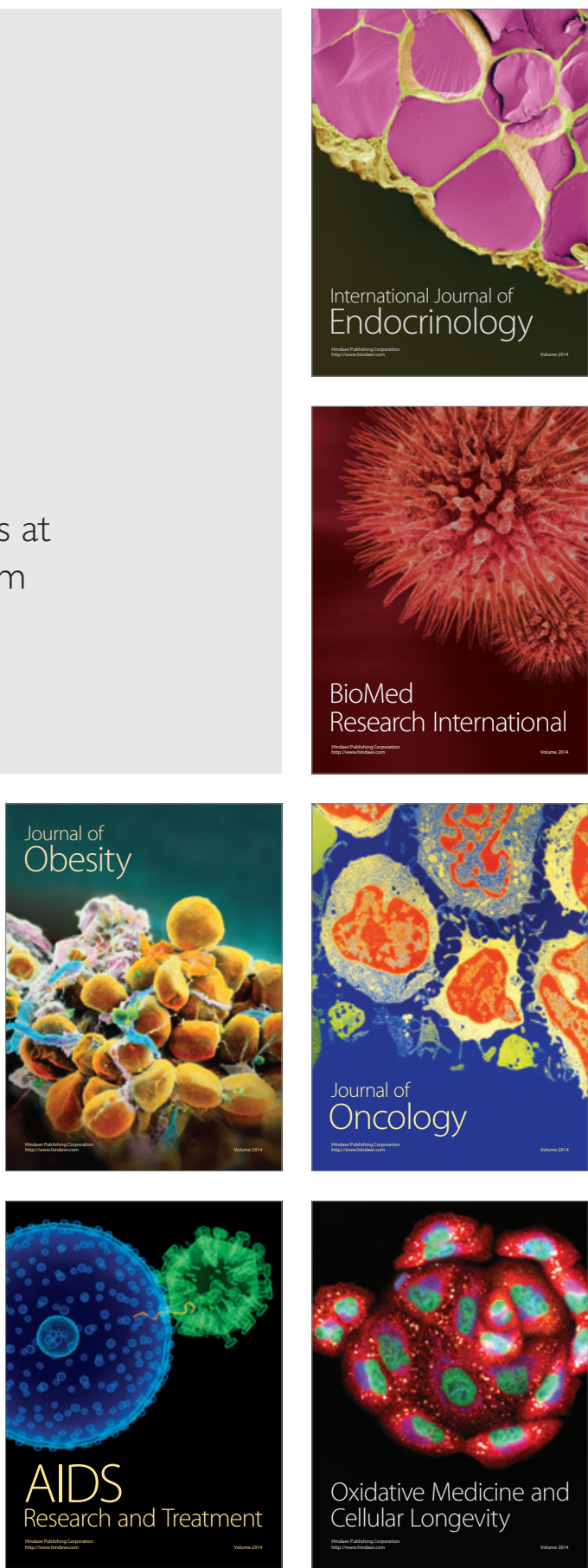